\title{
Lovejoy and Osburn's Overpartitions
}

\section{Sabuj Das}

Senior Lecturer, Department of Mathematics, Raozan University College, BANGLADESH

Corresponding Contact:

Email: sabujdas.ctg@gmail.com

\section{ABSTRACT}

In 2008, Lovejoy and Osburn defined the generating function for $\bar{P}(n)$.In 2009, Byungchan Kim defined the generating function for $P_{2}(n)$. This paper shows how to discuss the generating functions for $P(n)$ and $P_{2}(n)$. Byungchan Kim also defined $P_{k}(n)$ with increasing relation and overpartition congruences mod 4,8 and 64. In 2006, Berndt found the relation $d_{1,4}(n)-d_{3,4}(n)$ has two values with certain restrictions and various formulae by the common term $\sigma(\mathrm{n})$. This paper shows how to prove the four Theorems about overpartitions modulo 8. These Theorems satisfy the arithmetic properties of the overpartition function modulo 8.

Keywords: Convenience, congruent, modulo 8, prime factorizations, parity

\section{INTRODUCTION}

In this paper we give some related definitions of overpartition, $\omega(\lambda), P_{k}(n), d(n)$, $\mathrm{d}_{\mathrm{i}, 4}(\mathrm{n}), \sigma(\mathrm{n})$ and $\chi(\mathrm{n})$. We discuss the generating functions for $\bar{P}(n)$ and $\mathrm{P}_{2}(\mathrm{n})$. We analyze various relations $\bar{P}(n)=\sum_{\mathrm{k}} 2^{\mathrm{k}} \mathrm{p}_{\mathrm{k}}(\mathrm{n}), \overline{\mathrm{P}}(3 \mathrm{n}+2) \equiv 0(\bmod 4), \overline{\mathrm{P}}(4 \mathrm{n}+3) \equiv 0$ $(\bmod 8)$,

$$
\begin{aligned}
& P(8 n+7) \equiv 0(\bmod 64) \text {, } \\
& \mathrm{d}_{1,4}(\mathrm{n})-\mathrm{d}_{3,4}(\mathrm{n})=\left\{\begin{array}{l}
\left(\mathrm{r}_{1}+1\right) \ldots\left(\mathrm{r}_{\mathrm{k}}+1\right), \text { if } \mathrm{s}_{\mathrm{i}} \text { 's are even integers, } \\
0, \text { otherwise, }
\end{array}\right. \\
& \bar{P}(n) \equiv 2 d_{1,4}(n)-2 d_{3,4}(n)-2 \chi(n)-2 \sigma(n)+4 d(n)(\bmod 8), \\
& \sigma(\mathrm{n})=\left(2^{\mathrm{a}+1}-1\right) \prod_{\mathrm{i}}\left(\sum_{\mathrm{m}=0}^{\mathrm{r}_{\mathrm{j}}} \mathrm{p}_{\mathrm{i}}^{\mathrm{m}}\right) \prod_{\mathrm{j}}\left(\sum_{\mathrm{m}=0}^{\mathrm{s}_{\mathrm{j}}} \mathrm{q}_{\mathrm{j}}^{\mathrm{m}}\right) \text {, and } \sigma(n) \equiv\left\{\begin{array}{l}
\left(r_{1}+1\right) \ldots\left(r_{k}+1\right)(\bmod 4) i f a=0 \\
3\left(r_{1}+1\right) \ldots\left(r_{k}+1\right)(\bmod 4), \text { otherwise, }
\end{array}\right.
\end{aligned}
$$

respectively. We prove the four Theorems about overpartitions modulo 8 with certain conditions of $n$. 


\section{Some Related Definitions}

Overpartition: An overpartition of $\mathrm{n}$ is a partition of $\mathrm{n}$ in which the first occurrence of a part may be overlined. Let $\bar{P}(n)$ denote the number of overpartitions of an integer $n$. For convenience, define

$\overline{\mathrm{P}}(0)=1$. For example

$\mathrm{n}$

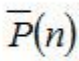

$1: \quad 1, \overline{1}$

$2: \quad 2, \overline{2}, \quad 1+1, \overline{1}+1$

$3: \quad 3, \overline{3}, 2+1, \overline{2}+1,2+\overline{1}, \overline{2}+\overline{1}, 1+1+1, \overline{1}+1+1$

$4: \quad 4, \overline{4}, 3+1, \overline{3}+1,3+\overline{1}, \overline{3}+\overline{1}, 2+2, \overline{2}+2,2+1+1$,

$$
\overline{2}+1+1,2+\overline{1}+1, \overline{2}+\overline{1}+1,1+1+1+1, \overline{1}+1+1+1
$$

Similarly we get;

$\overline{\mathrm{P}}(5)=24, \overline{\mathrm{P}}(6)=40, \overline{\mathrm{P}}(7)=64, \ldots$

$\omega(\lambda)$ : An ordinary partition $\lambda$, there are $2^{\omega(\lambda)}$ distinct overpartitions, where $\omega(\lambda)$ is the number of distinct parts in $\lambda$. For example if $\lambda=2+1+1 ; \omega(\lambda)=2$, there are four overpartitions $[2+1+1, \overline{2}+1+1,2+\overline{1}+1, \overline{2}+\overline{1}+1]$ then. $2^{\omega(\lambda)}=2^{2}=4$.

$P_{k}(n)$ [ Byungchan $\mathrm{Kim}(2009)$ ] : The number of partitions of $\mathrm{n}$ such that the number of distinct parts is exactly $k$. For example $P_{2}(6)=6$ since there are six partitions like $5+1$, $4+2,4+1+1,3+1+1+1,2+2+1+1,2+1+1+1+1$.

$\mathrm{d}(\mathrm{n}) \quad$ : The number of the divisors of $\mathrm{n}$.

$d_{i, 4}(n)$ [Alladi (1997)] :The number of the divisors of $n$ which are congruent to $i$ modulo 4.

$\sigma(\mathrm{n}) \quad$ :The sum of the divisors of $\mathrm{n}$.

$\chi(\mathrm{n}):$ The term is defined by $\chi(\mathrm{n})=\left\{\begin{array}{l}\text {, where } \mathrm{n} \text { is a square of an integer, } \\ \mathrm{o} \text {, otherwise. }\end{array}\right.$

For example, $\chi(6)=0, \chi(9)=1, \ldots \ldots$

\section{The Generating Function}

The generating function [Byungchan $\operatorname{Kim}(2009)$ ] for $\overline{\mathrm{P}}(\mathrm{n})$ is given by

$$
\prod_{n=1}^{\infty} \frac{\left(1+x^{n}\right)}{\left(1-x^{n}\right)}=\frac{(1+x)\left(1+x^{2}\right)\left(1+x^{3}\right) \ldots \ldots}{(1-x)\left(1-x^{2}\right)\left(1-x^{3}\right) \ldots}
$$




$$
\begin{aligned}
& =\left(1+\mathrm{x}+\mathrm{x}^{2}+2 \mathrm{x}^{3}+2 \mathrm{x}^{4}+3 \mathrm{x}^{5}+\ldots \ldots\right) \quad\left(1+\mathrm{x}+\mathrm{x}^{2}+3 \mathrm{x}^{3}+5 \mathrm{x}^{4}+\ldots . .\right) \\
& =1+2 \mathrm{x}+3 \mathrm{x}^{2}+8 \mathrm{x}^{3}+14 \mathrm{x}^{4}+24 \mathrm{x}^{5}+40 \mathrm{x}^{6}+64 \mathrm{x}^{7}+\ldots \ldots \\
& =\overline{\mathrm{P}}(\mathrm{o})+\overline{\mathrm{P}}(1) \mathrm{x}+\overline{\mathrm{P}}(2) \mathrm{x}^{2}+\overline{\mathrm{P}}(3) \mathrm{x}^{3}+\overline{\mathrm{P}}(4) \mathrm{x}^{4}+\ldots \ldots \ldots . . \\
& =\sum_{n=0}^{\infty}-\bar{P}(n) x^{n} .
\end{aligned}
$$

The generating function [Byungchan $\operatorname{Kim}(2009)$ ] for $P_{2}(n)$ is given by

$$
\begin{aligned}
& \left(\sum_{k \geq 1} \frac{x^{k}}{1-x^{k}}\right)^{2}-\sum_{k \geq 1}\left(\frac{x^{k}}{1-x^{k}}\right)^{2} \\
& =\left(\frac{x}{1-x}+\frac{x^{2}}{1-x^{2}}+\ldots\right)^{2}-\left[\left(\frac{x}{1-x}\right)^{2}+\left(\frac{x^{2}}{1-x^{2}}\right)^{2}+\ldots\right] \\
& =2 \frac{\mathrm{x}}{1-\mathrm{x}} \cdot \frac{\mathrm{x}^{2}}{1-\mathrm{x}^{2}}+2 \cdot \frac{\mathrm{x}}{1-\mathrm{x}} \cdot \frac{\mathrm{x}^{3}}{1-\mathrm{x}^{3}}+2 \cdot \frac{\mathrm{x}}{1-\mathrm{x}} \cdot \frac{\mathrm{x}^{4}}{1-\mathrm{x}^{4}}+\ldots . \\
& =2 \mathrm{x}^{3}\left(1+\mathrm{x}+\mathrm{x}^{2}+\ldots\right)\left(1+\mathrm{x}^{2}+\ldots\right)+2 \mathrm{x}^{4}(1+\mathrm{x}+\ldots .)\left(1+\mathrm{x}^{3}+\ldots .\right)+\ldots \\
& =2 x^{3}+4 x^{4}+10 x^{5}+\ldots . \\
& =2 P_{2}(3) x^{3}+2 P_{2}(4) x^{4}+2 P_{2}(5) x^{5}+\ldots \\
& =\sum_{n \geq 1} 2 P_{2}(n) x^{n} . \text { For convenience } \mathrm{P}_{2}(1)=0 \text { and } \mathrm{P}_{2}(2)=0 .
\end{aligned}
$$

\section{VARIOUS RELATIONS ABOUt OVERPARTITIONS}

A) If $\mathrm{n}=6, \overline{\mathrm{P}}(6)=40, \mathrm{P}_{1}(6)=4$ (like : $\left.6,3+3,2+2+2,1+1+1+1+1+1\right), \mathrm{P}_{2}(6)=6$, and

$$
\mathrm{P}_{3}(6)=1
$$$$
\therefore \quad 2 \mathrm{P}_{1}(6)+2^{2} \mathrm{P}_{2}(6)+2^{3} \mathrm{P}_{3}(6)
$$$$
=2.4+4.6+8.1
$$$$
=8+24+8=40=\mathrm{P}(6)
$$

$\therefore \overline{\mathrm{P}}(6)=2 \mathrm{P}_{1}(6)+2^{2} \mathrm{P}_{2}(6)+2^{3} \mathrm{P}_{3}(6)$.

So we can write $\bar{P}(n)=\sum_{k} 2^{k} P_{k}(n)$ [Andrews (1967)].

Reducing this modulo 8 , we obtain $\bar{P}(n) \equiv 2 P_{1}(n)+2^{2} P_{2}(n)(\bmod 8)$, it is seen that $P_{1}(n)=d(n)$, when $\mathrm{d}(n)$ is the number of the divisors of $\mathrm{n}$ including 1 and $n$.

B) We get;

$$
\overline{\mathrm{P}}(2)=4, \overline{\mathrm{P}}(5)=24, \ldots . . \text { i.e., } \overline{\mathrm{P}}(2)=4 \equiv 0(\bmod 4), \overline{\mathrm{P}}(3+2)=24 \equiv 0(\bmod 4), \ldots
$$


We can conclude that $\overline{\mathrm{P}}(3 \mathrm{n}+2) \equiv 0(\bmod 4)$.

C) We get;

$\overline{\mathrm{P}}(3)=8, \overline{\mathrm{P}}(7)=64, \ldots .$. i.e. $\overline{\mathrm{P}}(3)=8 \equiv 0(\bmod 8), \overline{\mathrm{P}}(4+3)=64 \equiv 0(\bmod 8)$.

We can conclude that $\overline{\mathrm{P}}(4 n+3) \equiv 0(\bmod 8)$.

D) We get;

$\overline{\mathrm{P}}(7)=64, \overline{\mathrm{P}}(15)=1408, \ldots$ i.e. $\overline{\mathrm{P}}(7)=64 \equiv 0(\bmod 64), \overline{\mathrm{P}}(8+7)=1408 \equiv 0(\bmod 64), \ldots$

We can conclude that $\bar{P}(8 n+7)) \equiv 0(\bmod 64)$. [Lovejoy et al (2008)]

E) Let $n=2^{\mathrm{a}} \mathrm{p}_{1}^{\mathrm{r}_{1}} \ldots \mathrm{p}_{\mathrm{k}}^{\mathrm{r}_{\mathrm{k}}} \mathrm{q}_{1}^{\mathrm{s}_{1}} \ldots . \mathrm{q}_{1}^{\mathrm{s}_{1}}$, ,

If $d_{i, 4}(n)$ is the number of the divisors which are congruent to i modulo 4 .

Now if $n=9=3^{2}=3^{\mathrm{s}_{1}}$ when $\mathrm{s}_{1}=2$ is the even integer

$\therefore \quad \mathrm{d}_{1,4}(9)=2, \mathrm{~d}_{3,4}(9)=1$, then $\mathrm{d}_{1,4}(9)-\mathrm{d}_{3,4}(9)=2-1=1$.

Again if $n=6=2.3=2^{\mathrm{a}} \cdot 3^{\mathrm{s}_{1}}$ when $\mathrm{a}=1$ and $\mathrm{s}_{1}=1$

$\therefore \quad \mathrm{d}_{1,4}(6)=1, \mathrm{~d}_{3,4}(6)=1$,

Then $\mathrm{d}_{1,4}(6)-\mathrm{d}_{3,4}(6)=1-1=0$.

We can conclude that if $\mathrm{n}$ has the prime factorization $2^{\mathrm{a}} \mathrm{p}_{1}^{\mathrm{r}_{1}} \ldots \ldots \mathrm{p}_{\mathrm{k}}^{\mathrm{r}_{\mathrm{k}}} \mathrm{q}_{1}^{\mathrm{s}_{1}} \ldots \ldots . . \mathrm{q}_{1}^{\mathrm{s}_{1}}$, where the $\mathrm{p}_{\mathrm{i}}{ }^{\prime} \mathrm{s}$ are primes congruent to 1 modulo 4 and $\mathrm{q}_{\mathrm{j}}$ 's are primes congruent to 3 modulo 4 , then $d_{1,4}(n)-d_{3,4}(n)=\left\{\begin{array}{l}\left(\mathrm{r}_{1}+1\right) \ldots\left(\mathrm{r}_{\mathrm{k}}+1\right), \text { if } \mathrm{s}_{\mathrm{i}}{ }^{\prime} \mathrm{s} \text { are even integers } \\ 0, \text { otherwise [Fortin et al (2005)]. }\end{array}\right.$

F) We get; $d_{1,4}(9)=2$ (like, the divisors are 1 and 9)

$\mathrm{d}_{3,4}(9)=1,($ like, the divisor is 3$)$

Now we get; $2 \mathrm{~d}_{1,4}(9)-2 \mathrm{~d}_{3,4}(9)-2 \chi(9)-2 \sigma(9)+4 \mathrm{~d}(\mathrm{n})$

$=2 \times 2-2 \times 1-2 \times 1-2 \times 13+4 \times 3$

$=-14 \equiv 2(\bmod 8)$, but $\bar{P}(9)=154 \equiv 2(\bmod 8)$.

$\therefore \quad \overline{\mathrm{P}}(9) \equiv 2 \mathrm{~d}_{1,4}(9)-2 \mathrm{~d}_{3,4}(9)-2 \chi(9)-2 \sigma(9)+4 \mathrm{~d}(9)(\bmod 9)$.

We can conclude that, $\overline{\mathrm{P}}(n) \equiv 2 \mathrm{~d}_{1,4}(\mathrm{n})-2 d_{3,4}(n)-2 \chi(n)-2 \sigma(n)+4 d(n)(\bmod 8)$. [Byungchan Kim(2009)]

G) If $n=10=2.5=2^{\mathrm{a}} 5^{\mathrm{r}_{1}}$ where $\mathrm{a}=1$ and $\mathrm{r}_{1}=1$ 


$$
\begin{array}{rlrl}
\therefore \sigma(10) & =\left(2^{2}-1\right)\left(5^{0}+5^{1}\right) & \text { but } \quad \sigma(10)=\frac{2^{2}-1}{2-1} \cdot \frac{5^{2}-1}{5-1} \\
= & 3(1+5) & =\frac{3}{1} \cdot \frac{24}{4} & \\
= & 18 & =18
\end{array}
$$

We can conclude that

$$
\sigma(n)=\left(2^{a+1}-1\right) \prod_{i}\left(\sum_{m=0}^{r_{i}} p_{i}^{m}\right) \prod_{j}\left(\sum_{m=0}^{s_{j}} q_{j}^{m}\right) \cdot \text { [Andrews (1967)] }
$$

H) We get, $\mathrm{n}=9=3^{2}=2^{\mathrm{a}} \cdot 3^{\mathrm{s}_{1}}$ where $\mathrm{a}=0$ and $\mathrm{s}_{1}=2$

$$
\begin{aligned}
& \sigma(9)=\frac{3^{2}-1}{3-1}=\frac{26}{2}=13 \equiv 1(\bmod 4)=(0+1) \equiv\left(\mathrm{r}_{1}+1\right)(\bmod 4) \\
& \text { again if } \mathrm{n}=10=2 \cdot 5=2^{\mathrm{a}} \cdot 5^{\mathrm{r}_{1}} \text { where } \mathrm{a}=1 \text { and } \mathrm{r}_{1}=1 \\
& \begin{aligned}
\sigma(10)=\frac{2^{2}-1}{2-1} \cdot \frac{5^{2}-1}{5-1}=3 \cdot \frac{24}{4}=18 \equiv 2(\bmod 4) \equiv 6(\bmod 4)=3.2=3(1+1) \\
\equiv 3\left(\mathrm{r}_{1}+1\right)(\bmod 4) .
\end{aligned}
\end{aligned}
$$

We can write that

$$
\sigma(n)=\left\{\begin{array}{l}
\left(r_{1}+1\right) \ldots .\left(r_{k}+1\right) \quad(\bmod 4) \text { if a }=0 \\
3\left(r_{1}+1\right) \ldots . .\left(r_{k}+1\right)(\bmod 4), \text { otherwise. [Fortin et al (2005)] }
\end{array}\right.
$$

\section{THEOREM}

Let $n$ be an integer, then

1) $\bar{P}(n) \equiv 0(\bmod 8)$, where $\mathrm{n}$ is not a square of an odd integer or an even integer and is not a double of a square.

2) $\quad \bar{P}(n) \equiv 2(\bmod 8)$, if $\mathrm{n}$ is a square of an odd integer.

3) $\bar{P}(n) \equiv 4(\bmod 8)$, if $\mathrm{n}$ is a double of a square

4) $\bar{P}(n) \equiv 6(\bmod 8)$, if $\mathrm{n}$ is a square of an integer.

Proof: From above we get;

$$
\chi(n)=\left\{\begin{array}{l}
1, \text { when } n \text { is a square of an integer, } \\
0, \text { otherwise. }
\end{array}\right.
$$

$$
\bar{P}(n) \equiv 2\left(d_{1,4}(n)-d_{3,4}(n)\right)-2 \chi(n)-2 \sigma(n)+4 d(n)(\bmod 8), \ldots
$$

where, $d_{i, 4}(n)$ is the number of the divisors which are congruent to i modulo 4 .

Now we will consider the three cases according to the parity of $r_{i}$ and $s_{j}$

Case 1: There is an $s_{j}$ that is odd and $r_{i}$ is any integer, then 


$$
\mathrm{d}_{1,4}(\mathrm{n})-\mathrm{d}_{3,4}(\mathrm{n})=0 \quad \chi(\mathrm{n})=\mathrm{o} \text { and } \mathrm{d}(\mathrm{n}) \equiv 0(\bmod 8) .
$$

From (1), we get

$$
\begin{aligned}
& \bar{P}(n) \equiv 2\left(d_{1,4}(n)-d_{3,4}(n)\right)-2 \chi(n)-2 \sigma(n)+4 d(n)(\bmod 8), \\
& \equiv 0-2 \times 0-2 \sigma(\mathrm{n})+0(\bmod 8) \\
& \text { or } \bar{P}(n) \equiv-2 \sigma(\mathrm{n})(\bmod 8) \ldots . .(2)
\end{aligned}
$$

[since if $\mathrm{n}=6=2.3=2^{\mathrm{a}} \cdot 3^{\mathrm{s}_{1}}$ where $\mathrm{a}=1$ and $s_{1}$ in an odd integer, then $\mathrm{d}_{1,4}(6)-\mathrm{d}_{3,4}(6)=0$ and $\chi(6)=0$ where 6 is not a square, and $d(6)=d(2.3)=(1+1)(1+1)=4$

$\therefore \quad 4 \mathrm{~d}(6)=4.4=16 \equiv 0(\bmod 8)]$.

From relation $\mathrm{G}$ ) we get;

$$
\begin{gathered}
\sigma(n)=\left(2^{a+1}-1\right) \prod_{i}\left(\sum_{m=0}^{r_{i}} p_{i}^{m}\right) \prod_{j}\left(\sum_{m=0}^{s_{j}} q_{j}^{m}\right) \text { [Berndt(2006)] } \\
\quad\left[\text { since } \mathrm{s}_{\mathrm{j}}{ }^{\prime} \mathrm{s} \text { are odd integers, so } \sum_{\mathrm{m}=0}^{\mathrm{s}_{\mathrm{j}}} \mathrm{q}_{\mathrm{j}}^{\mathrm{m}} \equiv 0(\bmod 4) .\right. \\
\therefore \quad \sigma(n) \equiv o(\bmod 4) \text { and } 2 \sigma(n) \equiv 0(\bmod 8)] .
\end{gathered}
$$

From (2) we can conclude that $\bar{P}(n) \equiv 0(\bmod 8)$ for such $n$.

Case 2: All $s_{j}$ 's are even and there is an $r_{i}$ that is odd.

Then, $\mathrm{d}_{1,4}(\mathrm{n})-\mathrm{d}_{3,4}(\mathrm{n})=\left(\mathrm{r}_{1}+1\right) \ldots\left(\mathrm{r}_{\mathrm{k}}+1\right), \chi(\mathrm{n})=0$ where $\mathrm{n}$ is not a square and 4 $\mathrm{d}(\mathrm{n}) \equiv 0(\bmod 8)$.

From (1) we get;

$$
\begin{aligned}
\bar{P}(n) \equiv & 2\left(r_{1}+1\right) \ldots\left(r_{k}+1\right)-2 \sigma(\mathrm{n})(\bmod 8) \ldots . .(3) \\
& {\left[\text { since if } n=5.3^{2}=45 \mathrm{~d}(45)=\mathrm{d}\left(5.3^{2}\right)=(1+1) \cdot(2+1)=2.3=6\right.} \\
\therefore \quad & 4 \mathrm{~d}(45)=4.6=24 \equiv 0 \quad(\bmod 8)]
\end{aligned}
$$

and $\sigma(n) \equiv\left(r_{1}+1\right) \ldots\left(r_{k}+1\right) \quad(\bmod 4)$, where $s_{j}{ }^{\prime}$ s are even $r_{i}{ }^{\prime} s$ are odd and $a=0$.

From (3), we can conclude that

$\bar{P}(n) \equiv 0(\bmod 8)$, where $n$ is not a square of an odd integer or an even integer and is not a double of a square. Hence the Theorem 1 .

[Numerical example 1: If $n$ is not a square of an odd integer or an even integer and is not a double of a square. We get; $\bar{P}(3)=8, \bar{P}(5)=24, \ldots$

$$
\therefore \bar{P}(3)=8 \equiv 0(\bmod 8), \bar{P}(5)=24 \equiv 0(\bmod 8), \ldots
$$

We can conclude that $\bar{P}(n) \equiv 0(\bmod 8)$,for such $n$.]

Case 3: All the $r_{i}$ 's and $s_{j}{ }^{\prime} s$ are even.

Suppose that $\mathrm{a}$ is o. Then $\mathrm{n}$ is a square. 
By (1) we deduce that

$$
\bar{P}(n) \equiv 2\left(\mathrm{r}_{1}+1\right) \ldots\left(\mathrm{r}_{\mathrm{k}}+1\right)-2-2 \sigma(\mathrm{n})+4(\bmod 8)
$$

[since $d_{1,4}(n)-d_{3,4}(n)=\left(r_{1}+1\right) \ldots\left(r_{k}+1\right)$ where $s_{j}{ }^{\prime}$ s are even and $\chi(n)=1$ where $\mathrm{n}$ is a square of an integer, $\mathrm{d}(\mathrm{n}) \equiv 1(\bmod 8)$ and also, $\sigma(\mathrm{n}) \equiv\left(\mathrm{r}_{1}+1\right) \ldots\left(\mathrm{r}_{\mathrm{k}}+1\right)(\bmod 4)$ where $r_{i}{ }^{\prime} s$ and $s_{j}{ }^{\prime} s$ are even and also $\left.a=0\right]$

From (4) we get; $\bar{P}(n) \equiv 2\left(\mathrm{r}_{1}+1\right) \ldots\left(\mathrm{r}_{\mathrm{k}}+1\right)+2-2\left(\mathrm{r}_{1}+1\right) \ldots\left(\mathrm{r}_{\mathrm{k}}+1\right)(\bmod 8)$.

$\therefore \quad \bar{P}(n) \equiv 2(\bmod 8)$, when $\mathrm{n}$ is a square of an odd integer. Hence the Theorem 2 .

[Numerical example 2: If $n$ is not a square of an odd integer,

We get; $\bar{P}(1)=2, \bar{P}(9)=154, \ldots$

$$
\therefore \bar{P}(1)=2 \equiv 2(\bmod 8), \bar{P}(9)=154 \equiv 2(\bmod 8), \ldots
$$

We can conclude that $\bar{P}(n) \equiv 2(\bmod 8)$,for such $n$.]

Suppose that a is odd. Then $\mathrm{n}$ is a double of square.

From (1) we get;

$$
\bar{P}(n) \equiv 2\left(\mathrm{r}_{1}+1\right) \ldots\left(\mathrm{r}_{\mathrm{k}}+1\right)-2 \sigma(\mathrm{n})(\bmod 8) . \text { [Berndt(2006)] }
$$

[since $d_{1,4}(n)-d_{3,4}(n)=\left(r_{1}+1\right) \ldots\left(r_{k}+1\right)$ where $r_{i}$ 's and $s_{j}$ 's are even integers.

$$
\chi(\mathrm{n})=\mathrm{o} \text {, where } \mathrm{n} \text { is not a square of an integer. }
$$

If $\mathrm{n}=2.3^{2} \cdot 5^{2}$

$\therefore \quad \mathrm{d}(\mathrm{n})=(1+1) \cdot(2+1) \cdot(2+1)=18$

$\therefore \quad 4 \mathrm{~d}(\mathrm{n})=4.18=72 \equiv 0(\bmod 8)]$

$$
\therefore \quad \bar{P}(n) \equiv 2\left(\mathrm{r}_{1}+1\right) \ldots\left(\mathrm{r}_{\mathrm{k}}+1\right)-2.3\left(\mathrm{r}_{1}+1\right) \ldots\left(\mathrm{r}_{\mathrm{k}}+1\right)(\bmod 8)
$$

[since $\sigma(\mathrm{n}) \equiv 3\left(\mathrm{r}_{1}+1\right) \ldots\left(\mathrm{r}_{\mathrm{k}}+1\right)(\bmod 4)$, where a is not zero]

$$
\begin{aligned}
\bar{P}(n) & \equiv-4\left(\mathrm{r}_{1}+1\right) \ldots\left(\mathrm{r}_{\mathrm{k}}+1\right)(\bmod 8) \\
& \equiv 4\left(\mathrm{r}_{1}+1\right) \ldots\left(\mathrm{r}_{\mathrm{k}}+1\right)(\bmod 8) \\
& \equiv 4(\bmod 8) .
\end{aligned}
$$

[since $r_{i}{ }^{\prime} s$ and $s_{j}{ }^{\prime} s$ are even integers so, $\left(r_{1}+1\right) \ldots\left(r_{k}+1\right) \equiv 1(\bmod 8)$ ] [Fortin et al (2005] $\therefore \quad \bar{P}(n) \equiv 4(\bmod 8)$, when $\mathrm{n}$ is a double of a square. Hence the Theorem 3 .

[Numerical example 3: If $n$ is a double of a square. We get; $\bar{P}(2)=4, \bar{P}(8)=100, \ldots$

$$
\therefore \bar{P}(2)=4 \equiv 4(\bmod 8), \bar{P}(2.4)=100 \equiv 4(\bmod 8), \ldots
$$

We can conclude that $\bar{P}(n) \equiv 4(\bmod 8)$, for such $n$.]

Suppose that a is even. Then $\mathrm{n}$ is a square of an even integer.

From (1) we get; $\bar{P}(n) \equiv 2\left(\mathrm{r}_{1}+1\right) \ldots\left(\mathrm{r}_{\mathrm{k}}+1\right)-2-2 \sigma(\mathrm{n})+4(\bmod 8)$ 
[since $\mathrm{d}_{1,4}(\mathrm{n})-\mathrm{d}_{3,4}(\mathrm{n})=\left(\mathrm{r}_{1}+1\right) \ldots\left(\mathrm{r}_{\mathrm{k}}+1\right)$ where $\mathrm{r}_{\mathrm{i}}{ }^{\prime} \mathrm{s}$ and $\mathrm{s}_{\mathrm{j}}$ 's are even integers, $\chi(\mathrm{n})=1$, where $\mathrm{n}$ is a square of an integer and $\mathrm{d}(\mathrm{n}) \equiv 1(\bmod 8)]$.

or $\bar{P}(n) \equiv 2\left(\mathrm{r}_{1}+1\right) \ldots\left(\mathrm{r}_{\mathrm{k}}+1\right)+2-2.3\left(\mathrm{r}_{1}+1\right) \ldots\left(\mathrm{r}_{\mathrm{k}}+1\right)(\bmod 8)$

[since $\sigma(\mathrm{n}) \equiv 3\left(\mathrm{r}_{1}+1\right) \ldots\left(\mathrm{r}_{\mathrm{k}}+1\right)(\bmod 4)$, where $\mathrm{a} \neq 0$ ]

or $\bar{P}(n) \equiv-4\left(\mathrm{r}_{1}+1\right) \ldots\left(\mathrm{r}_{\mathrm{k}}+1\right)+2(\bmod 8)$

$$
\begin{aligned}
& \equiv 4\left(\mathrm{r}_{1}+1\right) \ldots\left(\mathrm{r}_{\mathrm{k}}+1\right)+2(\bmod 8) \\
& \equiv 4.1+2(\bmod 8)
\end{aligned}
$$

[since $\mathrm{r}_{\mathrm{i}}{ }^{\prime} \mathrm{s}$ and $\mathrm{s}_{\mathrm{j}}{ }^{\prime} \mathrm{s}$ are even integers so $\left(\mathrm{r}_{1}+1\right) \ldots\left(\mathrm{r}_{\mathrm{k}}+1\right) \equiv 1(\bmod 8)$ ].

$\therefore \quad \bar{P}(n) \equiv 6(\bmod 8)$, when $\mathrm{n}$ is a square of an even integer. Hence the Theorem 4 .

[Numerical example 4 : If $n$ is a square of an even integer. We get; $\bar{P}(4)=14, \ldots$

$$
\therefore \bar{P}(4)=14 \equiv 6(\bmod 8), \ldots
$$

We can conclude that $\bar{P}(n) \equiv 6(\bmod 8)$, for such $n$.]

\section{Conclusion}

In this study we have analyzed various relations $\bar{P}(n)=\sum_{\mathrm{k}} 2^{\mathrm{k}} \mathrm{p}_{\mathrm{k}}(\mathrm{n}), \overline{\mathrm{P}}(3 \mathrm{n}+2) \equiv 0$ $(\bmod 4)$,

$$
\begin{aligned}
& \overline{\mathrm{P}}(4 \mathrm{n}+3) \equiv 0(\bmod 8), \overline{\mathrm{P}}(8 \mathrm{n}+7) \equiv 0(\bmod 64), \\
& d_{1,4}(n)-d_{3,4}(n)=\left\{\begin{array}{l}
\left(\mathrm{r}_{1}+1\right) \ldots\left(\mathrm{r}_{\mathrm{k}}+1\right), \text { if } \mathrm{s}_{\mathrm{i}}{ }^{\mathrm{s}} \text { are even integers, } \\
0, \text { otherwise }
\end{array}\right. \\
& \overline{\mathrm{P}}(\mathrm{n}) \equiv 2 \mathrm{~d}_{1,4}(\mathrm{n})-2 \mathrm{~d}_{3,4}(\mathrm{n})-2 \chi(\mathrm{n})-2 \sigma(\mathrm{n})+4 \mathrm{~d}(\mathrm{n})(\bmod 8),
\end{aligned}
$$

respectively with the help of numerical examples. We have verified the four Theorems about overpartitions modulo 8 with numerical examples.

\section{ACKNOWLEDGMENT}

It is a great pleasure to express my sincerest gratitude to our respected professor Md. Fazlee Hossain, Department of Mathematics, University of Chittagong, Bangladesh.

\section{REFERENCES}

Ahmad, M. (2013). Homogeneous Number System and Reciprocal Symmetric Algebra. Asian Journal

Of Applied Science And Engineering, 2(1), 92-99. Retrieved from http://journals.abc.us.org/index.php/ajase/article/view/2.10\%28M\%29 
Ahmad, M., \& Talukder, M. (2013). Correspondence between Reciprocity and Discreteness. Asian Journal Of Applied Science And Engineering, 2(1), 16-19. Retrieved fromhttp://journals.abc.us.org/index.php/ajase/article/view/2.2M\%26G

Alladi K., A fundamental invariant in the theory of partitions, in: Topics in Number Theory (University Park, PA, 1997), Kluwer Acad, Pubi, Dordrecht, 1999, pp.101-113

Andrews G.E., Enumerative proofs of certain q-identities, Glasg. Math.J.B(1967)33-40

Berndt B.C., Number Theory in the Spirit of Ramanujan, American Mathematical Society, Providence, RI, 2006.

Byungchan Kim, A short note on the overpartition function, Discrete Mathematics 309,(2009), $2528-2532$.

Das S, Mohajan HK. The Number of Vector Partitions of $\mathrm{n}$ (Counted According to the weight) with the Crank m International Journal of Reciprocal Symmetry and Theoretical Physics. 2014;1(2):91-105.

Das, S. (2014). Congruence Properties of Andrews'SPT- Function. ABC Journal Of Advanced Research, 3(2), 47-56. Retrieved from http://journals.abc.us.org/index.php/abcjar/article/view/6.5

Duviryak A. Bound States in the Compactified Gravity International Journal of Reciprocal Symmetry and Theoretical Physics. 2014;1(2):80-90.

Fortin J.F.Jacob P., Mathieu P., Jagged partitions, Ramanujan J. 10 (2005) 215-235.

Lovejoy J. and Osburn R. ,Rank differences for overpartitions, Q.J.Math. 59(2), 257-273,2008.

Mohajan HK. Gravitational Collapse of a Massive Star and Black Hole Formation International Journal of Reciprocal Symmetry and Theoretical Physics. 2014;1(2):125-140.

Mohajan, H. (2014). Upper Limit of the Age of the Universe with Cosmological Constant. International Journal Of Reciprocal Symmetry And Theoretical Physics, 1(1), 43-68. doi:10.15590/ijrstp/2014/v1i1/53723

Talukder, M., \& Ahmad, M. (2013). Wave Particle Dualism for Both Matter and Wave and NonEinsteinian View of Relativity. Asian Journal Of Applied Science And Engineering, 2(1), 80-91. Retrieved fromhttp://journals.abc.us.org/index.php/ajase/article/view/2.9G\%26M

\section{Source of Support: Nil, No Conflict of Interest: Declared}

This article is is licensed under a Creative Commons Attribution-NonCommercial 4.0 International License.

Attribution-NonCommercial (CC BY-NC) license lets others remix, tweak, and build upon work non-commercially, and

although the new works must also acknowledge \& be non-commercial. 